This article was downloaded by: [Australian National University]

On: 08 August 2013, At: 15:55

Publisher: Routledge

Informa Ltd Registered in England and Wales Registered Number: 1072954 Registered

office: Mortimer House, 37-41 Mortimer Street, London W1T 3J H, UK

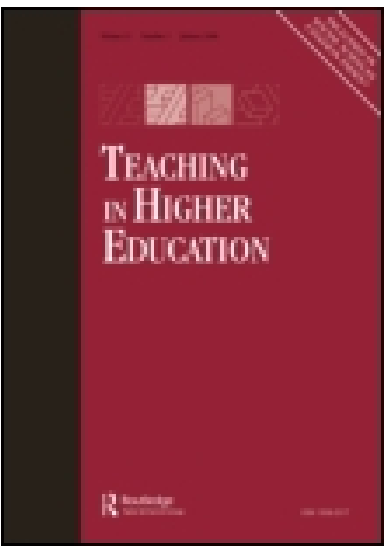

\title{
Teaching in Higher Education
}

Publication details, including instructions for authors and subscription information:

http:// www.tandfonline.com/loi/ cthe20

\section{Differentiating undergraduate research}

\author{
Jack Bowers ${ }^{a} \&$ Ashvin Parameswaran ${ }^{b}$ \\ a Academic Skills and Learning Centre, The Australian National \\ University (ANU) , Canberra, 0200 , Australia \\ ${ }^{b}$ College of Asia and the Pacific, The Australian National \\ University (ANU) , Canberra, 0200 , Australia \\ Published online: $08 \mathrm{~J}$ an 2013.
}

To cite this article: J ack Bowers \& Ashvin Parameswaran (2013) Differentiating undergraduate research, Teaching in Higher Education, 18:5, 453-464, DOI: 10.1080/ 13562517.2012.752731

To link to this article: http:// dx. doi.org/ 10.1080/ 13562517.2012.752731

\section{PLEASE SCROLL DOWN FOR ARTICLE}

Taylor \& Francis makes every effort to ensure the accuracy of all the information (the "Content") contained in the publications on our platform. However, Taylor \& Francis, our agents, and our licensors make no representations or warranties whatsoever as to the accuracy, completeness, or suitability for any purpose of the Content. Any opinions and views expressed in this publication are the opinions and views of the authors, and are not the views of or endorsed by Taylor \& Francis. The accuracy of the Content should not be relied upon and should be independently verified with primary sources of information. Taylor and Francis shall not be liable for any losses, actions, claims, proceedings, demands, costs, expenses, damages, and other liabilities whatsoever or howsoever caused arising directly or indirectly in connection with, in relation to or arising out of the use of the Content.

This article may be used for research, teaching, and private study purposes. Any substantial or systematic reproduction, redistribution, reselling, loan, sub-licensing, systematic supply, or distribution in any form to anyone is expressly forbidden. Terms \& Conditions of access and use can be found at http://www.tandfonline.com/page/termsand-conditions 


\title{
Differentiating undergraduate research
}

\author{
Jack Bowers $^{\mathrm{a} *}$ and Ashvin Parameswaran ${ }^{\mathrm{b}}$ \\ ${ }^{a}$ Academic Skills and Learning Centre, The Australian National University (ANU), \\ Canberra 0200, Australia; ${ }^{\mathrm{b}}$ College of Asia and the Pacific, The Australian National University \\ ( ANU), Canberra 0200, Australia
}

(Received 26 January 2012; final version received 9 October 2012)

\begin{abstract}
The work of undergraduates has been generally perceived in terms of coursework rather than research; research, rather, has been considered the domain of postgraduates and academics. This study collected data from interviews with 80 undergraduates at an Australian research university. The results suggest that undergraduates perceive research along a spectrum, from developmental - where research is framed by an intellectual hierarchy from undergraduate to postgraduate to academic - to discrete perceptions of research, which frame research as non-hierarchical. These two frames - the developmental and the discrete have implications for universities choosing to mainstream undergraduate research (UR) opportunities.
\end{abstract}

Keywords: higher education; undergraduate research; students' perceptions

\section{Introduction}

'Research' is a term embedded with multiple connotations, values and associations. Often used as a dichotomous signifier to 'teaching', there is an understanding that research is conducted by qualified academics, sometimes with 'apprentice' postgraduates providing assistance. This conception of research, which largely precludes undergraduates, has had profound implications for the way in which universities have developed and nurtured their communities. Integrating research into undergraduate courses, this paper suggests, would significantly improve both the undergraduate experience generally and broader educational outcomes.

There is considerable variation amongst academics' perceptions of research. Brew (2001a, 24-26, 2001b) identified four distinct conceptions - domino, trading, layer and journey. Kiley and Mullins (2005) also identified four different categories technical, creative/innovative, integrating complexity and new ways of seeing - and a similar four were identified by Pitcher and Akerlind (2009) - explorative, spatial, constructive and organic. Each of these studies implicitly assumes that the 'research' is conducted by either postgraduates or lecturers.

The value of investigating undergraduate conceptions of research has only recently been appreciated. Of course, the influential report by the Boyer Commission on Educating Undergraduates in the Research University (1998) emphasised undergraduate research (UR) as an integral means of transforming the learning experience. Katkin's (2003) study also identified the unique position of research

*Corresponding author. Email: jack.bowers@anu.edu.au 
universities for UR: 'their multiple missions; the high number and wide range of baccalaureate and doctoral degrees they offer; a defining commitment to creating knowledge, which shapes the faculty's values and attitudes; the presence of graduate students; and enormous diversity within the university community population' (22). Although later research clearly establishes the viability of UR in other kinds of higher education institutions (Malachowski 2003; Perez 2003), research universities remain critical catalysts for reinventing undergraduate education through UR (Merkel 2003).

This lack of interest in undergraduates' views on research reinforces the notion that undergraduates are presumed to know less, have less experience and have less power than lecturers and postgraduates to initiate change. Undergraduates are encouraged to feel that research is 'something quite separate from them, an optional extra and certainly not something over which they [are] consulted or informed' (Jenkins et al. 1998, 136). There is increasing recognition, however, of 'a need to open up the language of higher education to provide a sense of belonging for everyone who is participating in the university's educative ventures' (Brew 2006, 161-162). Lopatto (2004), for example, surveyed 1135 undergraduates from 41 institutions about the general benefits of UR. Dillner et al. (2011) in a study of chemistry majors, reports that 'students have been overwhelmingly positive about their education, particularly the research or capstone experience' (1626), and Gresty and Edwards-Jones (2012) found that, although 'the students' understanding of research-informed teaching in the survey varied considerably', their participation in the publication of an e-journal went hand-in-hand with the value they placed on research opportunities (157). Zamorski (2000) conducted an excellent study which probed the views of 108 undergraduates within the framework of research-led teaching in higher education. Being the first part of a longitudinal project, Levy and Petrulis (2012) conceptualised research as fundamental to inquiry-based learning. From a cohort of 29 undergraduate students from humanities and social science disciplines, Levy and Petrulis found several key benefits for undergraduates who perceive themselves as researchers. However, as Spronken-Smith and Walker (2010) have observed, the efficacy of inquiry-based learning is dependent on its context in disciplinary research. The matrix developed by Healey and Jenkins (2009) identified two research quadrants - researchtutored and research-based - as providing the most valuable contexts for learning. Our study indicates that 'research' is itself an activity encompassing a broad range of perceptions, which cover the four quadrants of the Healey and Jenkins matrix.

Two lines of inquiry can be pursued to include undergraduates' voices in relation to conceptions of research. First, in a similar vein to many of the studies cited earlier, undergraduates' conceptions of research can be documented, as in Falconer and Holcomb (2008). This research is also supported by Craney et al. (2011) who conducted a study of intensive UR programmes held over the summer break. They concluded that 'students who were involved for multiple summers also expressed more favourable attitudes toward research as a career option after graduation and toward the likelihood that they might publish their results' (107).

The second line of inquiry - and the one pursued in this study - directly examines undergraduates' conceptions of the similarities and differences between undergraduate, postgraduate and academic research. The body of this paper is structured in three sections. The first section provides the methodological details of the study. The second section critically summarises existing research on experimental and 
conceptual innovation (Galenson 2006) as a precursor to the categories developmental and discrete - that we propose. The third section provides evidence of these categories. Overall, we argue that while most undergraduates view undergraduate, postgraduate and academic research as developmental stages, a minority sees them as discrete entities.

\section{Methodology}

Primary data are drawn from a single research university located in Australia. Data collection was carried out via semi-structured interviews with undergraduates. Respondents were asked two open-ended questions: (1) 'In what ways is UR similar to or different from postgraduate research'? (2) 'In what ways is UR similar to or different from academic research'? The phrasing of all questions (e.g. 'academic research' versus 'research by academics' versus 'faculty research') was pilot tested with 12 undergraduates from the same population to ensure that their wording would make sense to the main sample. In total, the main sample comprised 68 undergraduates (none of whom were in the pilot sample).

The combined sample comprised 43 males and 37 females. The breakdown of respondents by year of study is as follows: 1st year (17), 2nd year (34), 3rd year (21) and honours (8). The breakdown of respondents by discipline is as follows (total exceeds 80 because of students enrolled in double degrees): Arts (31), Asian Studies (20), Commerce (21), Engineering (7), Law (15) and Science (9). As a qualitative sample sought by an open call for respondents, our aim is similar to the phenomenographic tradition which seeks to generate and classify variation in conceptions. While we occasionally report descriptive statistical data, it must be clarified that this is not a random sample from which inferences about the undergraduate population can be made. Future research that adopts a random sampling approach would complement our study. It could provide statistically significant correlations between the nature of undergraduates' involvement in research and the influence this involvement has on their conception of research (non-participant, developmental or discrete as detailed below). Alternatively, future research investigating staff perceptions of UR would also provide a useful complement to the present study.

Interviews were carried out by a team of 12 undergraduate researchers (who also formed the pilot sample). This approach is similar to Zamorski's in her project on research-led teaching and learning (Zamorski 2002). The benefit of this method, as she observes, is that it 'offered a privileged access to data from the...student body... [and] invited students to become integral to the whole process of research' (Zamorski 2002, 413).

Two statements were put to the sample ( $N=79$ due to incomplete information): 'The opportunity to engage in UR is available to all undergraduates' and 'The opportunity to engage in UR should be available to all undergraduates'. Responses were sought for each statement on a Likert scale of one (strongly disagree) to five (strongly agree). For the first statement, the key statistics read - mean (2.75), mode (2) and standard Deviation (1.25). For the second statement, the key statistics read mean (4.32), mode (5) and standard Deviation (0.98). 


\section{Results and discussion}

Generally, students responded by conceiving of research as either being a practice conducted on completion of received learning or, alternatively, as a practice which did not necessarily rely on hierarchical or institutional restrictions. While there were nuances and variety across the perceptions, discussed below, we have identified the received learning model as 'developmental' and the less scaffolded perception as 'discrete'. In reflecting on the observations of students, however, it became evident that different understandings of the role of innovation lay at the heart of their conceptual frameworks.

\section{Innovation}

How we perceive research is closely linked with how we understand the role of innovation. Galenson (2006) examines innovation in terms of experimental innovation and conceptual innovation; they are, in effect, precursors to the categories of developmental research and discrete research proposed in this paper. Galenson identifies his two archetypes - experimental innovation and conceptual innovation as they apply to artists in the modern era. Attached to each archetype is a specific conception of artistic practices and products (Galenson 2006, 4). Experimental artists conceive their practice as one of incremental improvement. They 'repeat themselves, painting the same subject many times, and gradually changing its treatment in an experimental process of trial and error' (Galenson 2006, 4). These artists conceive their products as developmental drafts in an ongoing search for expression within complexity. 'Each work leads to the next, and none is generally privileged over others' (Galenson 2006, 4). Paul Cezanne's art exemplifies experimental innovation:

For him [Cezanne], as I understand his work, the ultimate synthesis of a design was never revealed in a flash; rather he approached it with infinite precautions ... and always in fear lest a premature definition might deprive it of something of its total complexity. For him the synthesis was an asymptote toward which he was forever approaching it without quite reaching it. (Fry 1989, 3; cited in Galenson 2006, 53)

In contrast with experimental artists, conceptual artists conceive their practice as a process of execution in which major decisions have already been made, rather than a process of deliberation in which decisions are constantly being made, or a process of discovery in which new ideas are being generated. 'Conceptual innovations can usually be implemented immediately and completely,' and 'the conceptual artist's ability to consider a problem solved can free him to pursue new goals' (Galenson 2006, 5). Pablo Picasso's art exemplifies conceptual innovation. In the artist's own words:

I can hardly understand the importance given to the word research in connection with modern painting. In my opinion to search means nothing in painting. To find, is the thing.... When I paint my object is to show what I have found, not what I am looking for. The several manners I have used in my art must not be considered as an evolution or as steps toward an unknown ideal of painting....I have never made trials or experiments. Whenever I had something to say, I have said it in the manner in which I have felt it out to be said. Different motives inevitably require different methods of expression. (Barr 1946, 270-271; cited in Galenson 2006, 8-9) 
Galenson extends the application of the two archetypes by stating that there are strong parallels between the situation of the modern artist and that of the research scholar' (Galenson 2006, 17). Specifically, he points to the fact that scholarship and art, unlike more technical fields like bridge building, require 'perceiving a previously unrecognised problem, or formulating a previously recognised problem in a novel way, before creating a solution to it' (Galenson 2006, 17). This conception of the experimental and the innovative is also evident in an earlier work which examined the careers of Nobel laureates in economics (Weinberg and Galenson 2005). Combining quantitative analysis of citations with qualitative analysis of the work for which they were awarded the Nobel Prize, 31 laureates are classified as either experimental or conceptual innovators (Weinberg and Galenson 2005).

Galenson's work is not without its critics, and there are valid concerns regarding Galenson's attempts to create a predictive model which relates innovation to age (Tufte 2006, 148-151). However, the abundant qualitative evidence provided by Galenson and ignored by Tufte clearly demonstrates that the two archetypes do apply generally to conceptions of innovation practices and products in many professions.

When applied to undergraduates' conceptions of the similarities and differences between undergraduate, postgraduate and academic research, the archetypes help categorise two distinct ways of thinking about the relationship across these three types. An experimental view of innovation sees research as developmental. Undergraduate, postgraduate and academic research are tiered stages in a unified research narrative. Research practices and products improve over the trajectory (from undergraduate to postgraduate to academic) as researchers become better at their work and output. Alternatively, a conceptual view of innovation sees research as discrete. Undergraduate, postgraduate and academic research are not necessarily connected and do not share a linear research narrative. Research practices and products are distinct, with researchers working in different ways, which results in different outputs, across the different types. This concurs with Brew's phenomenographic study (2001b). Brew's 'domino' variation conceives of research as both 'a series of separate tasks, events, activities, problems, experiments, ideas, or questions, each of which is viewed as distinct' - overlapping with the 'discrete' category - and another layer in which the separate atomistic lists are linked together in linear patterns, which overlaps with the 'developmental' category (Brew 2001b, 24).

\section{Developmental}

Central to the conception of a developmental pathway is the presumption of an intellectual hierarchy. Academic research is seen as something better than postgraduate research, which in turn is seen to be better than UR. Foreshadowing this conception, Zamorski found that many academics believed that undergraduates had not made sufficient intellectual progress and did not possess sufficient maturity to be capable of engaging in research (Zamorski 2000, 14). Beyond, or perhaps because of, such perceptions, institutional structures 'support and sustain the idea that knowledge is a staged process' (Brew 2006, 44). Teaching students in year-groups and filtering admissions to allow only the most talented students to proceed to honours and doctoral research are two institutional mechanisms that reinforce a hierarchical view of knowledge (Brew 2006, 44-45). 
Responses from our sample were dominated by the developmental conception. 'UR is not original. It's more like research of other people's research. Limited research in a way. That's how I understand it' [2nd yr, Arts]. 'Undergraduates are starting at a different level from postgraduates because of difference in experience, difference in ability, difference in exposure' [2nd yr, Arts]. 'Postgraduate research is more... open to your own interpretation where you can go around and do your own research' [2nd yr, Arts/Asian Studies]. 'It [UR] can be well defined but not very complicated because it's in undergraduate level so it should be very simple. Not very complicated like honours' [1st yr, Arts]. 'Postgraduate is more in-depth.... and I think they give it more credibility because they think that these people doing postgraduate already have experience like an undergraduate level. They are mature and all that stuff'. [1st yr, Arts].

The perception, then, is that research about others' research is not genuine when, of course, research is always situated within - and in response to - a community of inquiry. The respondents' views are part of the developmental perspective that sees the UR experience as lower on the intellectual hierarchy and therefore requiring greater control and guidance, with increasing intellectual quality and freedom being provided as researchers progress. This developmental perspective is further reinforced in respondents' comments about the role of mentoring and supervisory relationships. Nearly all respondents who mentioned these relationships emphasised their central role in UR and their increasingly peripheral role in postgraduate and academic research. An illustrative example reads:

If it's a journey, the supervisor is sort of at the end of the journey whereas with the mentor you are always kept travelling. That's the main difference because in postgraduates, they don't need a mentor. They should only have a supervisor. And undergraduates' research definitely needs mentors ... And in terms of academics, I don't think they even need supervisors. (3rd yr, Science)

An interesting take on the developmental conception is the acknowledgement that sometimes development is not enough. Since research in this conception is tied to an intellectual hierarchy, some students may not posses the innate ability required no matter the training provided:

It's like music. You need to have an ear for pitch. If you are tone-deaf, no amount of music training is going to help. Research is like that as well ... for some it's a lost cause. Nothing is going to help because they're just not suited for research. (2nd yr, Science)

Overall, the responses suggest that the dominant conception of the relationship between undergraduate, postgraduate and academic research is developmental. In the interviews, it was also apparent that comparatively few respondents had clear ideas about academic research, and that the few ideas they did have conceived an especially narrow view of research. While this is not surprising, it is worth noting that exposure to the everyday work of academics doing research would provide undergraduates with a firmer basis from which to think about their own connection and positioning in relation to research experiences. Perhaps what is more surprising is that undergraduates seem unaware of the skills that they have developed through pre-university studies. As Brew notes $(2006,44)$, undergraduates 'have already had 
considerable experience in investigation, in project research and in inquiry-based learning', that is in discrete, non-hierarchical activities.

\title{
Discrete
}

Central to this conception is the notion that these types of research are really only loosely connected; the themes of intellectual hierarchy and tiered stages are absent or muted. Discrete conceptions are expressed in three ways.

First, some responses point out that, far from scaffolding learning, academic socialisation has a negative impact on the quality of research. Consequently, UR is seen as equivalent to - or even better than - postgraduate or academic research because it is not conditioned by academic norms and processes. Intellectual hierarchy is absent, or even reversed, placing this view firmly in the discrete conception. One example reads, 'Research that you do while you are an undergraduate student, so you only have a small background and volume of information ... you are unbiased' [1st yr, Science]. Another example suggests that undergraduates are advantaged by being fresh to academic mores:

\begin{abstract}
Research done by young, fresh minds that are uninfluenced by a full degree so they have a different perspective and a different angle than that of a honours or postgraduate student would have. Gives a unique perspective or something completely different to that than a postgraduate student would otherwise have, which I think is valuable to any study regime or research concept. (2nd yr, Commerce/Arts)
\end{abstract}

Second, some responses see UR as only loosely connected with the university. An 'activity that is to do with learning about new things. Getting out. Finding new things and compiling information. Trying to make sense of whatever the information that is available. If an undergraduate is doing that, that is research' [2nd yr, Arts]. A 3rd year Commerce student observed that:
My degree doesn't really require me to do research but since I am doing finance, I do my own research on finance and the markets. Like investment and stuff. What is Warren Buffet's investment strategy? So that's what I do right now by myself. It's not required by my lecturer, my degree. I do a lot of out-of-course research ... not really research but learning consistently whatever it may be. Learning a foreign language or reading newspapers or stuff like that. But that's not really researchy [sic]. (3rd yr, Arts)

When quizzed about postgraduate and academic research, all these respondents quoted here framed their responses only in terms of research pertaining to degrees, publications and other hallmarks of academia.

Another response looks beyond the university entirely to focus on commercial entities conducting research, which, in this respondent's opinion, falls under the category of research that undergraduates can and should be engaging in:

Companies do research.... and it's not because the people who are doing it have $\mathrm{PhDs}$ that it is valid. It's just because they've got a clear idea of where they are going and they got a job that they are doing. They have a clear path. One of the reasons why UR maybe at the moment doesn't have anything is because there is not a clear path. Not a clear path of like how you can get involved, what you can do. (2nd yr, Arts) 
Third, related to both categories discussed earlier, and by far the most commonly voiced strand of the discrete conception, is the notion that institutional constraints pose severe limitations to UR. In this view, UR is being held back because of the way in which it is structured and resourced by universities, for example: 'UR ... you're generally limited in your time. You're doing it in a much shorter timeframe with access to limited resources' [3rd yr, Commerce/Arts]. Another reads, 'I think there's differences in undergraduates and postgraduates between things like funding. I don't get the feeling that undergraduates would be able to get access to funding' [2nd yr, Arts]. Many respondents see UR as confined to coursework and see the coursework structure imposing artificial limitations on originality:

I think UR is predominantly about the process of doing research and it's predominantly course dependent... Particularly in a lot of Arts based courses you are discouraged. Like you cannot have an original thought ... you're not allowed to ... you can come to a conclusion on which side of the fence you sit on but you personally cannot bring out your own ideas. You can only agree or disagree. (3rd yr, Arts/Commerce)

Another response acknowledges the institutional restrictions on UR. 'Research is pretty much the same. But for an undergraduate it starts at a different level. You know the scope for an undergraduate, if not less than is certainly limited than postgraduate research' [2nd yr, Arts]. In the excerpt below, this respondent goes on to cite resource differentials, and his opinion that undergraduates and academics are working in different research frames, as reasons why UR is limited. No mention is made of intellectual hierarchy, thus placing this view firmly in the discrete conception:

Generically they are doing the same thing but undergraduates are starting at a different level from postgraduates.... And of course postgraduate students have more scope of publishing or presenting their work to a wider audience because of the resources they have, because of the credibility that they would enjoy over undergraduates because of the obvious reason that they're postgraduates. As far as academic research is concerned.... As compared to UR, undergraduates aren't under any sort of competition to produce a lot of stuff. Academic research as compared to UR is influenced by a lot of market factors which really doesn't affect UR. Like publishing. Journals and publishers have their own preferences in terms of what kind of research they want to publish what would sell.... In that way market forces influence how academic research is conducted. The scope of academic research is also dependent on how much money there is. (2nd yr, Arts)

The next response vehemently denies intelligence and, by extension, intellectual hierarchy as a limiting factor in UR:

It's got nothing to do for me with your intelligence. You can have some undergraduate students that may have had ten years' industry experience.... I've got people I do finance with and I'm sure they can produce something that's equally as good as any postgraduate student if they had the same time-frame to produce it in and the same access to resources and mentorship .... It's got nothing to do with intelligence or skills. (3rd yr, Arts/Commerce)

The last excerpt in this section indicates that moving away from the developmental conception is a struggle, even when one holds a discrete conception: 
It's sort of difficult because I'm trying to get away from this developmental idea about it because it seems really restrictive about what people can do no matter where they are. Like, you are just a postgraduate, you can't add as much as the head of the climate change institute or something like that. That's not necessarily true. There's a lot of intelligent people out there and just because they don't have a PhD yet, or just because they're not an associate professor or something, doesn't mean that they're not going to be adding valuable stuff. (2nd yr, Arts/Asian Studies)

The evidence in this section reinforces the discrete conception of the relationship between undergraduate, postgraduate and academic research. Although expressed in different ways, the common factor amongst these responses is the absence of intellectual hierarchy between undergraduate, postgraduate and academic research. Each type of research is seen as a different beast, distinct due to specific organisational configurations. Implicitly, these perceptions question the underlying premise that the hierarchy of academic qualification runs parallel with a hierarchy of research.

The value in understanding students' perceptions of research is that, when we combine it with the emerging evidence of the advantages of research-led pedagogies, benefits are gained for both the institution and its graduates. Numerous studies indicate that students who recognise the research elements of their study have increased engagement (Dillner et al. 2011; Harsh et al. 2011; Stephens et al. 2011) and improved their skills (Pacifici and Thomson 2011; Stephens et al. 2011). Our study also supports Pacifici and Thomson (2011) who note that, when students' perceptions around research are better understood, 'UR experiences [can] be tailored, promoted and implemented to best serve all students who are interested in pursuing UR in science' (54).

\section{Conclusion}

This paper has identified two categories - developmental and discrete - as foundational ways of thinking - underlying undergraduates' conceptions of the similarities and differences between undergraduate, postgraduate and academic research. At one end of a spectrum, the developmental conception is characterised by an intellectual hierarchy in which undergraduate, postgraduate and academic research are tiered stages in a research narrative. At the other end of the spectrum, in a discrete conception, undergraduate, postgraduate and academic research are unconnected and do not share a research narrative. Research practices and products are distinct, with researchers working in different ways, which results in different outputs, across the different types.

Conceptions are graded, implying degrees of developmental and discrete conceptions rather than extremes. Conceptions can also be non-exclusive when referring to different actors, arenas or aspects of research. The only correlation that stood out was that all 12 undergraduate researchers held discrete conceptions of research (many of them simultaneously held developmental conceptions). This may be the result of greater familiarity, experience and sophistication in relation to issues in UR. Across both conceptions, many undergraduates believe that UR can be mainstreamed further. This belief was not expressed as idle speculation or wishful thinking: it was a clear recognition of individual capabilities and a firm expectation of institutional learning environments. 
Many undergraduates enter university with the requisite intellectual qualifications to engage in research (Brew 2006, 44). The massification of higher education, a paradigm of lifelong learning, acceptance of mature age students, increasing numbers of students with multiple undergraduate degrees, technological advances that allow for alternative modes of study, and an increasingly information-literate generation mean that more students are beginning undergraduate degrees better prepared for research than ever before. The success of UR programmes at research universities, liberal arts colleges and community colleges (Boyd and Wesemann 2009; Karukstis and Elgren 2007; Kinkead 2003) also demonstrates the efficacy of learning environments in mainstreaming UR regardless of initial aptitude or institutional type.

This push to mainstream UR further has been expressed forcefully by others:

Unfortunately, the UR experience is often viewed too narrowly as an isolated component of the student's education, or as suitable for only some of the most advanced students... we argue that UR should, in fact, be at the centre of the undergraduate experience. (Hodge et al. 2007, 1)

Beyond exhortation, the solution for mainstreaming UR further has repeatedly been identified as a systemic redesign of curricula rather than superficial repackaging of existing initiatives (Brew 2006, 45; Zamorski 2000, 20). Healey and Jenkins argue that the task for 'national systems, institutions and departments is to reinvent and reshape the overall curriculum and other aspects of university structures' in order to make UR opportunities available for all students $(2009,122)$. Pedagogically, there is little doubt that mainstreaming UR - more research opportunities for more undergraduates - is desirable because it helps 'prepare students for a world which is uncertain, super-complex, unpredictable and, indeed, terrifying' (Brew 2006, 180). Inevitably, such changes mean unsettling the entrenched hierarchies.

Within a developmental conception, mainstreaming UR becomes difficult because trying to replicate watered down versions of academic and postgraduate research amongst undergraduates is an expensive proposition for all but small or wealthy universities. Provision of one-to-one mentoring, laboratory equipment, joint authorship of refereed publications, and other hallmarks of traditional postgraduate and academic research configurations require a substantial and ongoing investment of human, financial and logistical resources. Inevitably, only a small proportion of undergraduates can be engaged within this model because of resource limitations.

The discrete conception has two implications for mainstreaming UR. First, and most important, it signals the value of UR as an experience in itself: an experience that may be intellectually different but not inferior to traditional research configurations; an experience that may only be loosely associated with the university; an experience that may not provide a pathway to postgraduate or academic research; but an experience that is nevertheless valued by students and is pedagogically justifiable. Within a discrete conception, the process of mainstreaming UR shifts from replicating existing configurations to creating alternative configurations. The shift is from increasing provision of one-to-one mentoring, laboratory equipment, joint authorship of refereed publications and so on, towards radical redesigns of coursework, increased independent project work, problem-based learning and 
industry-related research that is relevant to the bulk of undergraduates who will never pursue a university research career.

Second, while a discrete conception does not abrogate universities' responsibilities to promote a developmental conception, new research configurations may allow for better allocations of resources. There is a shift from marginal efficiency towards effectiveness. For example, a supervisor may work on an individual basis with three or four students at a time in a traditional configuration. However, if the same time and effort were spent on redesigning a course within a research supportive curriculum, one faculty member could engage with and support 10 times more students with the same resources. Many case studies of alternative configurations have been described (see for example Boyd and Wesemann 2009; Karukstis and Elgren 2007).

Overall, a discrete conception may be helpful in devising alternative configurations of research engagement for universities that seek to mainstream UR. Especially for non-research-intensive universities that do not have a significant postgraduate emphasis, the discrete conception may prove a critical strategic direction for initiating and implementing alternative programmes and activities.

\section{References}

Boyer Commission on Educating Undergraduates in the Research University. 1998. Reinventing Undergraduate Education: A Blueprint for America's Research Universities. Stony-Brook, NY: State University of New York Stony-Brook.

Brew, A. 2001a. The Nature of Research: Inquiry in Academic Contexts. London: RoutledgeFalmer.

Brew, A. 2001b. "Conceptions of Research: A Phenomenographic Study." Studies in Higher Education 26 (3): 271-285.

Brew, A. 2006. Research and Teaching: Beyond the Divide. New York: Palgrave Macmillan.

Boyd, M. K., and J. L. Wesemann, eds. 2009. Broadening Participation in Undergraduate Research: Fostering Excellence and Enhancing the Impact. Washington, DC: Council on Undergraduate Research.

Craney, C., T. McKay, A. Mazzeo, J. Morris, C. Prigodich, and R. de Groot. 2011. "CrossDiscipline Perceptions of Undergraduate Research Experience." Journal of Higher Education 82 (1): 92-113.

Dillner, D. K., R. F. Ferrante, P. J. Fitzgerald, and M. J. Schroeder. 2011. "Integrated Laboratories: Laying the Foundation for Undergraduate Research." Journal of Chemical Education 88 (12): 1623-1629.

Falconer, J., and D. Holcomb. 2008. "Understanding UR Experiences from the Student Perspective: A Phenomenological Study of a Summer Research Program." College Student Journal 42 (3): 869-878.

Galenson, D. W. 2006. Old Masters and Young Geniuses: The Two Life Cycles of Artistic Creativity. Princeton, NJ: Princeton University Press.

Gresty, K. A., and A. Edwards-Jones. 2012. "Experiencing Research-Informed Teaching from the Student Perspective: Developing an Undergraduate e-Journal." British Journal of Educational Technology 43 (1): 153-162.

Harsh, J. A., A. V. Maltese, and R. H. Tai. 2011. "Undergraduate Research Experiences from a Longitudinal Perspective.” Journal of College Science Training 41 (1): 84-91.

Healey, M., and A. Jenkins. 2009. Developing Undergraduate Research and Inquiry. New York: Higher Education Academy.

Hodge, D., K. Pasquesi, M. Hirsh, and P. Lepore. 2007. From Convocation to Capstone: Developing the Student as Scholar. Keynote address at the Association of American Colleges and Universities Network for Academic Renewal Conference, Long Beach, California. Accessed August 27. www.aacu.org/meetings/undergraduate_research/documents/Keynote. pdf 
Jenkins, A., T. Blackman, R. Lindsay, and R. Paton-Salzberg. 1998. "Teaching and Research: Student Perspectives and Policy Implications." Studies in Higher Education 23 (2): 127-141.

Karukstis, K. K., and T. E. Elgren, eds. 2007. Developing and Sustaining a Research-Supportive Curriculum: A Compendium of Successful Practices. Washington, DC: Council on Undergraduate Research.

Katkin, W. 2003. "The Boyer Commission Report and its Impact on Undergraduate Research." New Directions for Teaching and Learning 93: 19-38.

Kiley, M., and G. Mullins. 2005. "Supervisors' Conceptions of Research: What are they? Scandinavian Journal of Educational Research 49 (3): 245-262.

Kinkead, J. 2003. "Learning Through Inquiry: An Overview of Undergraduate Research." New Directions for Teaching and Learning 93: 5-18.

Levy, P., and R. Petrulis. 2012. "How do First-Year University Students Experience Inquiry and Research, and What are the Implications for the Practice of Inquiry-Based Learning?" Studies in Higher Education 37 (1): 85-101.

Lopatto, D. 2004. "Survey of Undergraduate Research Experiences (SURE): First Findings." Cell Biology Education 3 (4): 270-277.

Malachowski, M. R. 2003. "A Research-Across-the-Curriculum Movement." New Directions for Teaching and Learning 93: 55-68.

Merkel, C. A. 2003. "Undergraduate Research at the Research Universities." New Directions for Teaching and Learning 93: 39-54.

Pacifici, L. B., and N. Thomson. 2011. "What do they Expect? A Comparison of Student Expectations and Outcomes of Undergraduate Research Experiences." Journal of College Science Training 41 (1): 54-60.

Perez, J. A. 2003. "Undergraduate Research at Two-Year Colleges." New Directions for Teaching and Learning 93: 69-78.

Pitcher, R., and G. Akerlind. 2009. "Post-Doctoral Researchers' Conceptions of Research: A Metaphor Analysis." International Journal for Researcher Development 1 (2): 1-14.

Spronken-Smith, R., and R. Walker. 2010. "Can Inquiry-Based Learning Strengthen the Links Between Teaching and Disciplinary Research? Studies in Higher Education 35 (6): 723-740.

Stephens, R. P., K. W. Jones, and M. V. Barrow. 2011. "The Book Project: Engaging History Majors in Undergraduate Research." History Teacher 45 (1): 65-80.

Tufte, E. 2006. Beautiful Evidence. Cheshire, CT: Graphics Press.

Weinberg, B. A., and D. W. Galenson. 2005. Creative Careers: The Life Cycles of Nobel Laureates in Economics (National Bureau of Economic Research Working Paper No. 11799). Accessed August 27. http://www.nber.org/papers/w11799

Zamorski, B. 2000. Research-Led Teaching and Learning in Higher Education. Norwich: Centre for Applied Research in Education, University of East Anglia.

Zamorski, B. 2002. "Research-Led Teaching and Learning in Higher Education." Teaching in Higher Education 7 (4): 411-427. 